
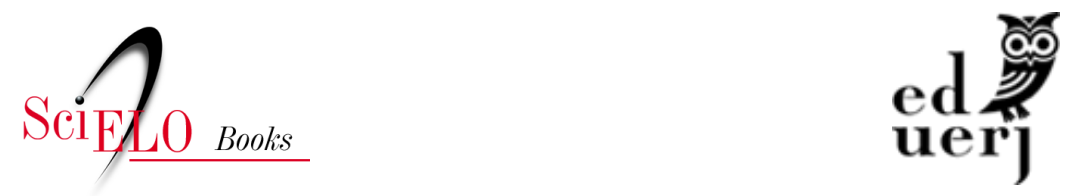

\title{
A pequena cidade e a universidade Dinâmicas intraurbanas de Cuité-PB
}

\author{
Maria Verônica de Azevedo Gomes \\ Josias de Castro Galvão
}

\section{SciELO Books / SciELO Livros / SciELO Libros}

GOMES, M. V. A., and GALVÃO, J. C. A pequena cidade e a universidade:

Dinâmicas intraurbanas de Cuité-PB. In: MAIA, D. S., and MARAFON, G. J., eds. Ensino superior e desenvolvimento regional: reconfigurando as relações entre as cidades e o campo [online]. Rio de Janeiro: EDUERJ, 2020, pp. 120-145. ISBN: 978-65-87949-08-6. https://doi.org/10.7476/9786587949086.0005.

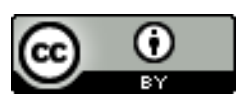

All the contents of this work, except where otherwise noted, is licensed under a Creative Commons Attribution 4.0 International license.

Todo o conteúdo deste trabalho, exceto quando houver ressalva, é publicado sob a licença Creative Commons Atribição 4.0.

Todo el contenido de esta obra, excepto donde se indique lo contrario, está bajo licencia de la licencia Creative Commons Reconocimento 4.0. 


\title{
A PEQUENA CIDADE E A UNIVERSIDADE: DINÂMICAS INTRAURBANAS DE CUITÉ-PB
}

\author{
Maria Verônica de Azevedo Gomes \\ Josias de Castro Galvão
}

\section{Introdução}

Os primeiros quatorze anos deste novo milênio foram marcados pela expansão das IFES - Instituições Federais de Ensino Superior para o interior brasileiro, possibilitando a criação e ampliação de cursos, vagas e campus universitários. Contudo, os impactos não se restringem ao âmbito educacional: a presença de IFES em médias e pequenas cidades vem provocando uma série de fenômenos socioespaciais.

De acordo com a Secretaria de Educação Superior (SESu), no período de 2003 a 2014, por meio da execução do Programa Nacional de Expansão do Ensino Superior do MEC - Ministério de Educação, ${ }^{11}$ foram criadas 18 novas universidades federais e 173 campus; houve o crescimento de $94 \%$ das matrículas nas universidades públicas da região Nordeste e de $76 \%$ da região Norte; e 9.306.877 pessoas concluíram o ensino superior em todo país.

Na Paraíba, a UFCG - Universidade Federal de Campina Grande assumiu o compromisso de atuar em parceria com este

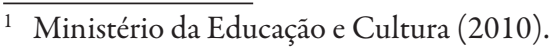


programa, idealizar e executar as ações necessárias. Logo, a SPE Secretaria de Projetos Estratégicos da UFCG planejou ações para instalar um centro universitário na então Microrregião do Curimataú Paraibano (área que atualmente faz parte da Região Geográfica Imediata de Cuité - Nova Floresta), ${ }^{22}$ por apresentar características socioeconômicas e educacionais de acordo com as prioridades definidas pelo MEC.

Cabe ressaltar que o processo de implantação desta instituição foi marcado pelo conflito, de sua posse, entre gestores municipais de Cuité e de Picuí. No primeiro semestre do ano de 2005, mesmo depois de uma audiência pública definir Cuité como sede do futuro campus da UFCG, a gestão municipal de Picuí se declara como interessada recebê-lo. Assim, trava-se uma disputa envolvendo sujeitos que fizeram uso do poder, de acesso às informações e de influências para defender seus interesses - ora comuns, ora contraditórios. Ao incentivar e promover manifestações populares, articular alianças políticas e criar estratégias em defesa e justificação da necessidade de sediar o novo campus da UFCG, tais sujeitos tornaram a Região Geográfica Imediata de Cuité - Nova Floresta um palco de conflitos entre forças sociais e políticas intermunicipais e estaduais.

O empenho nesse conflito pode ser considerado como uma demonstração da perspectiva que o campus universitário possibilitasse o crescente acesso à cultura e ao conhecimento e constituísse um meio de crescimento econômico. Principalmente, no que tange ao município de Cuité, que passava por um período de estagnação econômica quando comparado ao crescimento econômico outrora registrado.

No chamado período áureo do sisal, a produção e a exportação da fibra do agave permitiu o acúmulo e a concentração de capital

2 De acordo com o Instituto Brasileiro de Geografia e Estatística-IBGE (2017), esta região é formada pelos municípios de Cuité, Nova Floresta, Picuí, Frei Martinho, Sossego, Nova Palmeira, Pedra Lavrada, Damião, Baraúna e Frei Martinho. 
que se materializaram na paisagem da cidade, tornando-se visível nos investimentos infraestruturais, na expansão e diversificação dos serviços e do comércio, no crescimento demográfico e urbano do município, na fluídez cotidiana de mercadorias, informações e veículos e na intensificação das desigualdades sociais. Houve também a forte interferência na cultura e no modo de vida da população local, como exemplo: atividades culturais e tradicionais da parcela mais abastarda da sociedade que se tornaram mais glamorosas; alta na geração de emprego e forte atração de mão de obra.

Porém, a decadência dessa atividade levou a cidade à estagnação econômica e à inexistência de perspectivas em crescimento e desenvolvimento. Por décadas, essa realidade se estendeu, até que a possibilidade de implantação do CES em Cuité reacendeu as perspectivas de crescimento e desenvolvimento.

Durante o segundo semestre do ano de 2006, Cuité entra para a lista de cidades universitárias da Paraíba ao se iniciarem as atividades no Centro de Educação e Saúde - CES/UFCG. A presença do CES atribuiu uma nova funcionalidade a essa cidade, dinamizou as atividades imobiliárias, fortaleceu a economia e atraiu mais investimentos, serviços e pessoas. Portanto, intencionamos relatar e discutir como se desenrolaram estas questões do processo histórico de construção e reconstrução socioespacial urbana de Cuité, no período de 2006 a 2014.

\section{CES: a valorização do lugar}

O valor de cada lugar é modificado historicamente e espacialmente, pois depende de sua relação com o todo. Quanto mais sofisticados, eficientes e diversificados os bens e serviços ofertados, maior será o valor concedido a uma cidade. Isso também aumentará o seu poder de influência e de atração de novos fixos e novos fluxos. 
Quando uma atividade nova se cria em um lugar, ou quando uma atividade já existente aí se estabelece, o "valor" desse lugar muda e assim o "valor" de todos os lugares também muda, pois o lugar atingido fica em condições de exercer uma função que outros não dispõem e ganha através desse fato, uma exclusividade que é sinônimo de dominação; ou, modificando a sua própria maneira de exercer uma atividade preexistente, cria, no conjunto das localidades que também a exerce, um desequilíbrio quantitativo e qualitativo que leva a uma nova hierarquia ou, em todo o caso, a uma nova significação para cada um e para todos os lugares (Santos, 2012a, p. 66).

Ao possuir um campus universitário, ou seja, ao ofertar um serviço especializado e raro na escala regional, Cuité adquire uma nova funcionalidade e maior significância política, econômica e simbólica em relação aos municípios de seu entorno, tornando-se atrativa para investimentos em atividades e serviços.

Outras instituições de ensino também foram instaladas em Cuité, ofertando diversas modalidades educacionais. A tabela 8 expõe uma lista de instituições educacionais que passaram a funcionar a partir de 2006.

Tabela 8 - Cuité. Instituições educacionais particulares, inauguradas no período de 2006 a 2014, segundo modalidade de ensino e ano de instalação

\begin{tabular}{llc}
\hline Instituição & Modalidade & $\begin{array}{c}\text { Ano de } \\
\text { Instalação }\end{array}$ \\
\hline MILLENIUM & Educação Básica & 2008 \\
\hline IDEA & Educação Básica & 2010 \\
\hline CETES & Ensino Técnico & 2010 \\
\hline COGNITIVA & Graduação e Pós-Graduação & 2012 \\
\hline ECO & Ensino Técnico & 2014 \\
\hline
\end{tabular}

Fonte: Pesquisa de campo, 2014. 
No período investigado, foram implantadas cinco novas instituições particulares da área de ensino básico, técnico profissionalizante e superior. Essas instituições passaram a atender alunos provenientes não só de Cuité, mas de municípios paraibanos e potiguares circunvizinhos. Fato que representa a intensificação da influência regional de Cuité.

Ao investigar as instituições educacionais criadas depois de 2006, não foram contabilizadas as escolas públicas estaduais ou municipais; porém, cabe relatar que ao ano de 2014 iniciou-se construção do prédio da Escola Técnica Estadual de Cuité, que iniciou suas atividades ao ano de 2017.

As instituições apresentadas são um resultado de investimentos privados e públicos que passaram a incrementar a rede de serviços da área urbana cuiteense e, consequentemente, colaborar para sua especialização funcional e influência regional.

\section{CES: alterações demográficas}

Novos fluxos demográficos dirigiram-se para Cuité devido à oferta de trabalho e educação. Para constatar tal fato, realizamos uma pesquisa direta com discentes, técnicos administrativos e docentes do CES, a fim de distinguir suas origens e identificar a participação desses imigrantes no cotidiano da referida cidade.

Em 2014, o quadro efetivo de profissionais era composto por 115 docentes e por 44 servidores técnico-administrativos, e o quadro discente por 1.900 alunos matriculados nos cursos de graduação e pós-graduação, totalizando uma população de 2.059 pessoas.

$\mathrm{Na}$ execução da pesquisa, foram aplicados 530 questionários, o que equivale a um erro amostral de 3,7\% - a aplicação dos questionários foi realizada de acordo com o Método de Amostragem Probabilística: o tipo Aleatória e Simples.

A partir da tabulação dos resultados, constatou-se que apenas 15,6\% dos membros do CES habitava o município de Cuité antes 
de realizar alguma atividade neste campus. Logo, um total de $84,4 \%$ dos entrevistados não residia no município, sendo que $11 \%$ passou a morar definitivamente e 66\% ocupam habitações cuiteenses apenas nos períodos e dias letivos e 7,4\% realizam migração pendular.

Os membros do CES que se fazem presentes em Cuité durante os dias e/ou períodos de atividades acadêmicas contabilizam, em números absolutos, aproximadamente 1.585 pessoas. Como a zona urbana cuiteense é composta por cerca de 13.462 (IBGE, 2010) habitantes, conclui-se que há um aumento semanal de aproximadamente de 11,7\% nessa população.

A maioria desse grupo é oriunda de outros municípios da Paraíba, pois soma 50,4\% dos entrevistados. Desse modo, este campus universitário exerce maior força de atração demográfica em território intraestadual. Um total de 34\% dos investigados origina-se de outros estados brasileiros - deste total, contabilizam $22 \%$ de municípios potiguares, o que pode ser justificado, entre outros fatores, pela proximidade territorial entre o município de Cuité e o estado do Rio Grande do Norte.

Ao retornarem para os seus municípios de origem em finais de semana, feriados prolongados e/ou recessos, esses indivíduos colaboram para a intensificação do fluxo de pessoas, de informações, de veículos e para tornar mais animado o cotidiano da cidade. A respeito desse fenômeno, Carlos (2008b, p. 39) comenta que "dependendo da hora do dia, ou do dia da semana, a observação de um determinado lugar vai mostrar um determinado momento do cotidiano das pessoas que ai moram, trabalham e se locomovem. É o tempo da vida".

Os fluxos migratórios estão ligados a abrangentes conjuntos de causas e efeitos. Eles vão além do simples arbítrio individual, decorrem de fatores amplos - como as questões econômicas, habitacionais, de organização social e espacial do trabalho - e provocam uma série de alterações demográficas, econômicas, sociais e culturais. 
De acordo com Thomson (2002, p. 242), os movimentos migratórios se estabelecem "pelas maneiras em que as redes de trabalho e os estilos de vida do local de origem são recriados e modificados no novo mundo". De tal modo, as raízes da cultura, hábitos e valores diversos das pessoas que se instalam em Cuité se "misturam" com as características sociais do local, colaborando para a transformação do modo de vida e do cotidiano social.

\section{CES: uma nova demanda de bens e serviços?}

A massa demográfica que passou a frequentar ou residir em Cuité para trabalhar ou estudar no CES tem um papel significativo para as atividades comerciais e de serviços, públicos ou privados. Mesmo que permaneçam nesse município por um curto período de tempo, demandam oferta do setor comercial e de serviços para a realização de suas atividades e atendimento de necessidades diárias.

A realização do consumo para algumas dessas pessoas é assegurada, relativamente, pelo repasse de salários e bolsas estudantis, como demonstra a tabela 9, que apresenta a distribuição média anual de valores repassados aos alunos, aos professores, aos servidores técnicos administrativos e aos servidores terceirizados, durante o ano de 2013. 
Tabela 9 - Valores médios de bolsas e salários repassados aos alunos e profissionais do CES/UFCG, 2013

\begin{tabular}{|c|c|c|c|c|}
\hline \multicolumn{3}{|c|}{ CATEGORIAS ( $n^{\circ}$ de pessoas) } & $\begin{array}{c}\text { MÉDIA } \\
\text { MENSAL (R\$) } \\
\end{array}$ & $\begin{array}{c}\text { MÉDIA } \\
\text { MENSAL (R\$) } \\
\end{array}$ \\
\hline \multicolumn{3}{|c|}{ PROFESSORES (115) } & $855.445,84$ & $11.120 .795,00$ \\
\hline \multicolumn{3}{|c|}{$\begin{array}{c}\text { TÉCNICOS ADMINISTRATIVOS } \\
(44)\end{array}$} & $112.200,00$ & $1.458 .600,00$ \\
\hline \multicolumn{3}{|c|}{ DISCENTES (490) } & \multirow{10}{*}{$148.950,00$} & \multirow{10}{*}{$1.787 .400,00$} \\
\hline TIPO DE BOLSA & QTD. & $\begin{array}{c}\text { VALOR } \\
(\mathbf{R} \$)\end{array}$ & & \\
\hline REUNI & 273 & 250,00 & & \\
\hline MONITORIA & 90 & 300,00 & & \\
\hline PROLICEN & 3 & 300,00 & & \\
\hline PIBID & 56 & 400,00 & & \\
\hline PROBEX & 21 & 300,00 & & \\
\hline PIBIC & 24 & 300,00 & & \\
\hline PET & 16 & 400,00 & & \\
\hline PÓS-GRADUAÇÃO & 7 & $1.500,00$ & & \\
\hline \multicolumn{3}{|l|}{ TOTAL } & $1.116 .595,84$ & $14.366 .795,00$ \\
\hline
\end{tabular}

Fonte: CES/UFCG/Cuité, 2013.

Em 2013, um total de 159 profissionais efetivos recebeu remuneração trabalhista e 490 discentes receberam remuneração vinculada a alguma atividade estudantil. No referido ano, 31,5\% dos membros do CES foi contemplado pelo repasse de capital que tem como objetivo garantir a manutenção das atividades acadêmicas e pessoais de cada um. Visto que a maioria destas pessoas reside neste município nos períodos letivos ou passou a residir depois de vincular-se ao CES, há grande probabilidade de que ao menos parte desse capital seja utilizado na área urbana de Cuité. Ou seja, há uma forte tendência de que essas pessoas formem uma nova camada de consumidores. 
Diante desta questão, buscamos identificar a participação da comunidade do CES como consumidores do espaço intraurbano de Cuité. Assim, as reflexões e análises seguintes abordam a frequência de consumo de produtos e serviços e a presença destas pessoas em atividades culturais realizadas em Cuité. Essa análise considera quantitativamente todos os membros do CES, considerando que essas pessoas passaram a ter maior poder de consumo ao receber algum benefício financeiro repassado em forma de salários ou bolsas.

Foi questionado à comunidade sobre a frequência de consumo de bens duráveis (roupas, calçados, acessórios, utensílios domésticos, eletrodomésticos, móveis e eletroeletrônicos) e não duráveis (medicamentos, produtos de higiene pessoal e doméstica, e alimentos disponíveis em supermercados, minimercados, bodegas, padarias e frigoríficos). O gráfico 7 apresenta os resultados obtidos:

Gráfico 7 - Frequência de consumo da comunidade do CES/UFCG: produtos não duráveis e duráveis

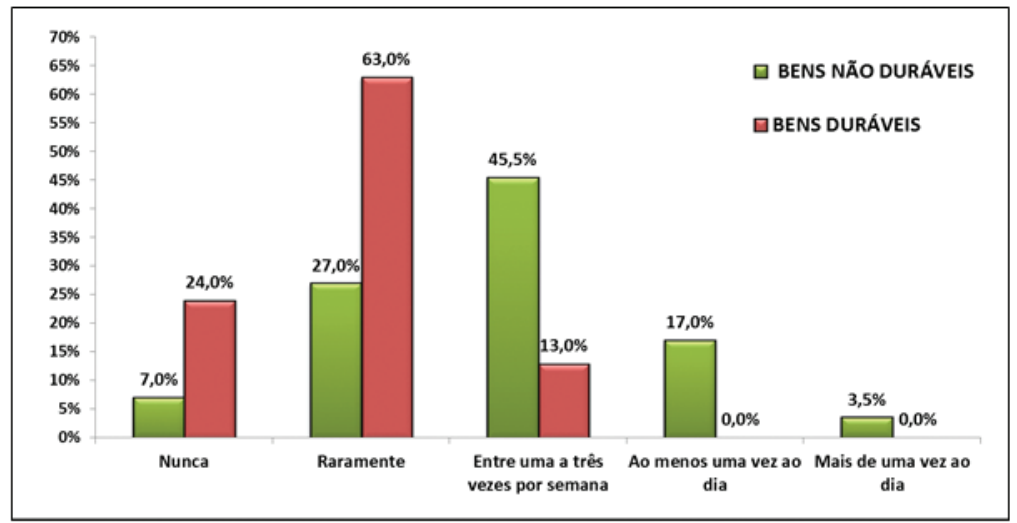

Fonte: Pesquisa direta, 2014.

É mais significativo o consumo de bens não duráveis em relação aos duráveis. Uma parcela de $45,5 \%$ da comunidade do CES 
realiza consumo de produtos não duráveis de uma a três vezes por semana, enquanto $17 \%$ ao menos uma vez ao dia e $3,5 \%$ compra estes produtos mais de uma vez ao dia. Desse modo, 66\% dos membros do CES realiza consumo com frequência em estabelecimentos comerciais que fornecem produtos básicos e essenciais para a manutenção da vida humana, como alimentos e medicamentos.

Com relação aos produtos duráveis, apenas $13 \%$ da população os adquire com frequência semanal nos estabelecimentos comerciais de Cuité. Cabe evidenciar que 7\% deste total (13\% de consumidores de bens duráveis) são pessoas que passaram a residir permanentemente na cidade após vincular-se ao CES.

No que se refere à utilização de serviços, o Gráfico 8 apresenta a frequência em que a comunidade do CES faz uso de serviços de clínicas particulares, de postos de saúde e hospitais públicos, de instituições financeiras (bancos e postos de atendimentos), de táxi e mototáxi, e de clínicas de beleza e estética.

Gráfico 8 - Frequência de consumo da comunidade do CES/UFCG: serviços diversos

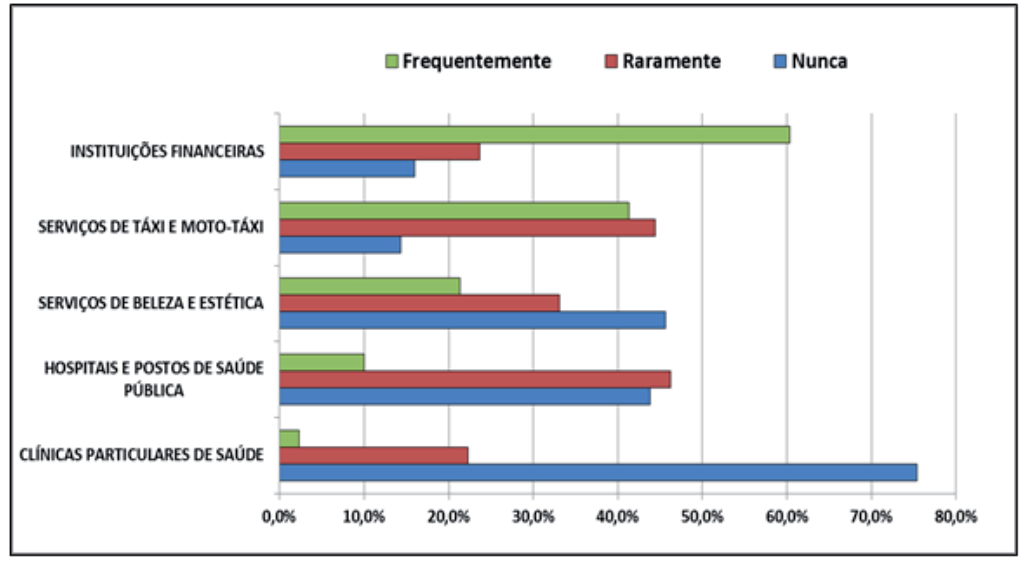

Fonte: Pesquisa direta, 2014. 
A comunidade do CES utiliza-se com mais frequência os serviços prestados por instituições financeiras e de táxi e mototáxi, visto que as atividades atreladas a estes serviços (exemplo: saque de dinheiro, pagamentos e deslocamento) são necessidades corriqueiras do cotidiano social. Outras questões a serem consideradas: no município de Cuité não há disponibilidade de transporte público, assim, o uso de mototáxis vem se tornando uma prática comum; e o uso deste serviço informal por parte dos membros do CES pode ter relação com a distância e acessibilidade desta instituição, localizada em zona rural municipal, a dois quilômetro da área central urbana. Vale salientar que apenas 13,3\% do grupo que usa com frequência os serviços de táxi e mototáxi já residia em Cuité antes de 2006, enquanto $86,7 \%$ dos usuários deste serviço passaram a residir somente após este período.

Os serviços de estética e beleza são usufruídos com frequência por 21,3\% dos entrevistados, $45,6 \%$ nunca fizeram uso desses tipos de serviços e 33,1\% informam que utilizam raramente. É importante ressaltar que $78,8 \%$ dos informantes que utiliza com frequência os serviços de estética e beleza não residiam em Cuité antes de estarem vinculados ao CES.

No que se refere ao uso de serviços de saúde, é significativa a parcela dos informantes que faz uso desses serviços raramente ou que nunca fez uso. Sendo, respectivamente, $46,2 \%$ e $43,8 \%$ relativo aos estabelecimentos públicos e 22,3\% e 75,4\% aos estabelecimentos particulares. As pessoas que usam com frequência os serviços de saúde já residiam em Cuité ou passaram a residir permanentemente após vincularem-se ao CES.

A frequência com que os membros do CES consumem em estabelecimentos fornecedores de refeições está exposta no gráfico 9: 
Gráfico 9 - Frequência de consumo da comunidade do CES/UFCG: serviços de lanchonetes e restaurantes

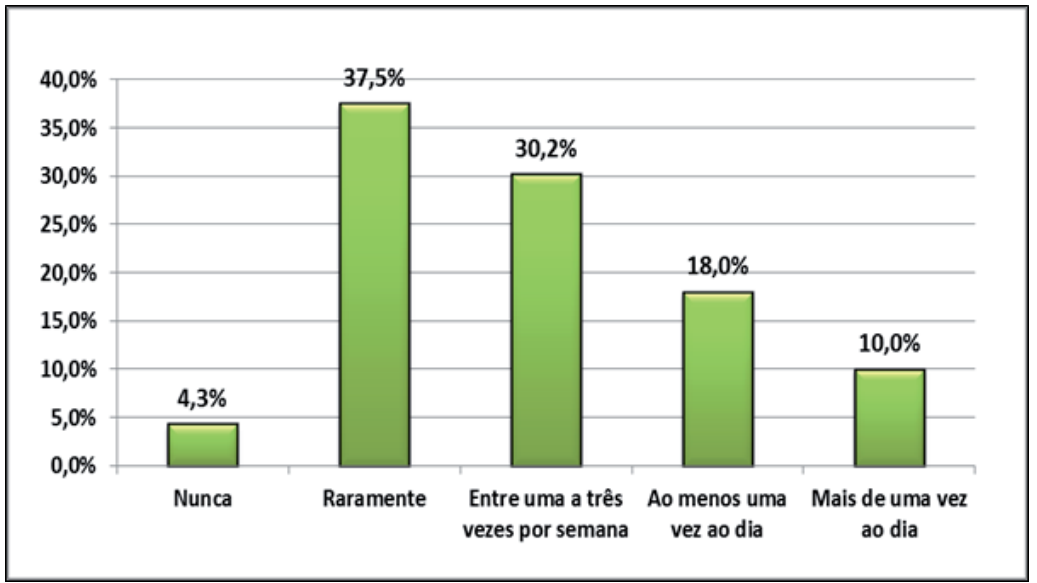

Fonte: Pesquisa direta, 2014.

Apenas 4,3\% da comunidade acadêmica do CES nunca realizou consumo em lanchonetes e restaurantes. De acordo com as informações adquiridas, fazem parte desse grupo alguns profissionais e alunos que residem em municípios próximos a Cuité, ou os alunos que se abrigam na Residência Universitária - onde são disponibilizadas as refeições diárias. Uma parcela de $37,5 \%$ dos informantes raramente frequenta esses tipos de estabelecimentos, enquanto $58,2 \%$ frequenta com uma assiduidade semanal, que varia de ao menos uma vez por semana até mais de uma vez ao dia.

A comunidade acadêmica do Centro de Saúde e Educação também se faz presente em atividades culturais realizadas em Cuité. O gráfico 10 detalha a participação desse grupo nas atividades seguintes: a) festas tradicionais e shows; b) apresentações artísticas e eventos realizados no teatro e visitas ao museu e; c) feiras e exposições de caráter científico ou artístico. 
Gráfico 10 - Participação da comunidade do CES/UFCG em atividades culturais

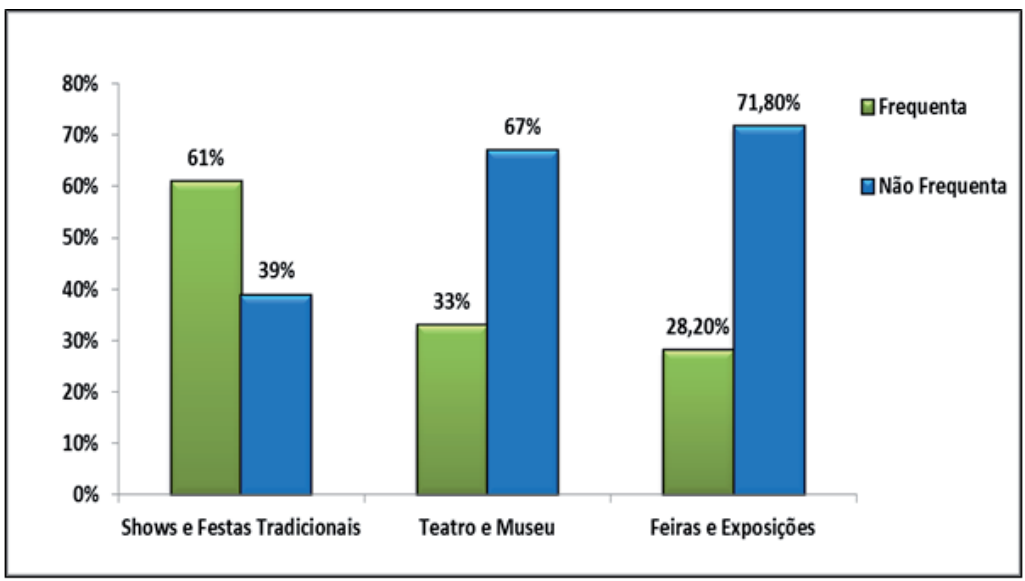

Fonte: Pesquisa direta, 2014.

Os dados apresentados acima revelam que a participação dos membros do CES é mais assídua em shows e festas tradicionais, que representa $61 \%$ da comunidade acadêmica. Apenas 33\% da comunidade do CES participam de atividades que ocorrem no teatro e no museu da cidade, e 28,2\% visitam feiras e exposições culturais. Uma média de aproximadamente $76 \%$ dos participantes dessas três categorias de atividades culturais faz parte do grupo de entrevistados que fixou moradia em Cuité para trabalhar ou estudar no campus da UFCG.

Os membros do CES vindos de outras cidades da Paraíba ou de outros estados brasileiros são, majoritariamente, solteiros e em faixa etária jovem. De acordo com os resultados obtidos, 80,8\% dos entrevistados são solteiros e 76,4\% estão da faixa etária entre 16 a 25 anos. Segundo Santos (2008, p. 83), o acréscimo de uma "população jovem exige maior administração e, ao menos teoricamente, a instalação de certo número de serviços”. 
Possivelmente relacionado a essas circunstâncias, depois do ano de 2006 tem ocorrido a instalação de equipamentos na área urbana cuiteense destinados ao lazer e a realização de eventos que englobam, principalmente, o público jovem. "Hoje o lazer é mediado pela mercadoria, que faz com que o cidadão, longe de se apropriar socialmente da cidade, através das brincadeiras, dos jogos, do ócio, se veja obrigado ao consumo da diversão" (Carlos, 2008b, p. 40).

No ano de 2009, foi inaugurada na cidade a Cuité Palace Casa Shows. Walkirio Simões Nobre, ${ }^{33}$ um dos primeiros sócios-proprietários, afirma que a escolha do investimento em Cuité foi “exclusivamente em função da presença do CES", por acreditarem que a vinda de estudantes jovens para a cidade estimularia a realização de eventos e seria um bom investimento.

O projeto total da Casa Shows Cuité Palace não foi concluído. Planejava-se a construção e um hotel, de uma área de lazer e de um parque de vaquejada. Porém, o hotel e a área de lazer nunca foram construídos; o parque de vaquejada funcionou poucos anos e foi extinto, e o terreno por ele ocupado está sendo loteado e se transformará no condomínio residencial Renascer da Serra. A casa de shows foi vendida a empresários ligados ao ramo de promoção de eventos, passando a chamar-se Cuité Hall.

Além da Cuité Hall, a Executive Casa de Eventos foi inaugurada em novembro de 2013, destinada à locação para realização de eventos, shows e festas. As festas têm ocorrido também em restaurantes e em ambientes bem inusitados: as piscinas de aluguel.

${ }^{3}$ Entrevista concedida em 02 jun. 2011, R. Adalto Soares, n. 552, Cuité - PB. 
Figura 16 - Folders de divulgação de eventos e locação das piscinas de aluguel

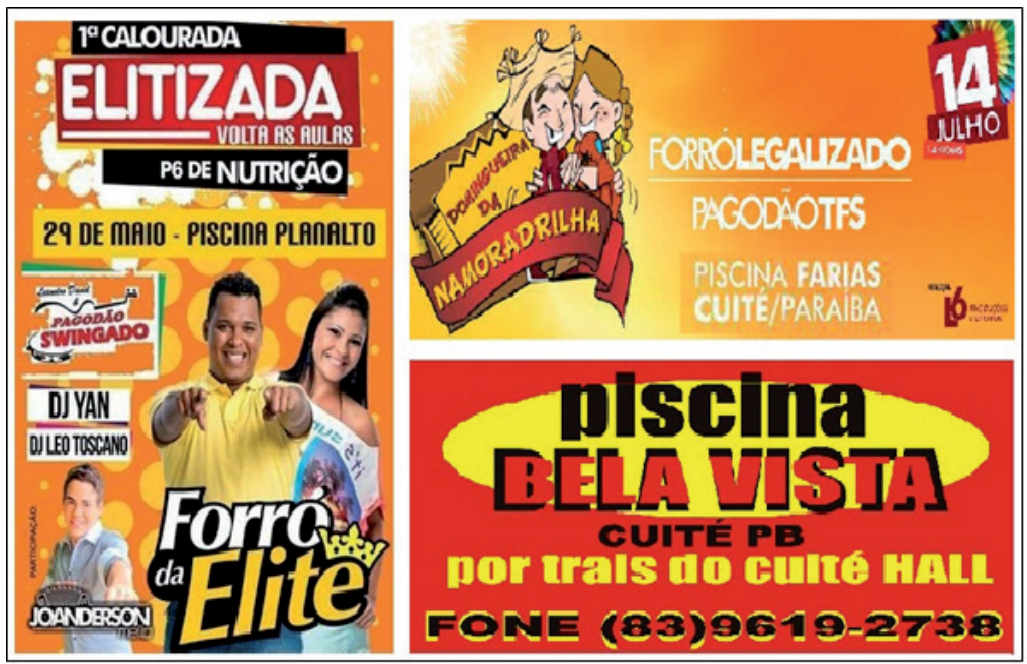

Fonte: Pesquisa de Campo, 2014.

Adaptada por: Maria Verônica de Azevedo Gomes.

As piscinas Farias, Planalto e Bela Vista são espaços de lazer disponíveis à locação para a população em geral. Não são os únicos espaços existentes na cidade, mais seis estabelecimentos semelhantes estão à disposição para locação. Situam-se na zona urbana cuiteense e comumente são usados para realização de shows, de festas e de calouradas que visam arrecadar fundos para turmas concluintes, além do uso pela comunidade local como forma de lazer.

A partir dos resultados expostos e discutidos, é possível afirmar que a presença comunidade acadêmica do CES suscitou no crescimento de consumidores e, consequentemente, na necessidade de novos investimentos. Essa população flutuante tem colaborado para o aumento da demanda de bens e serviços ofertados pelo mercado cuiteense, pois parte significativa deste grupo de consumidores são pessoas que não habitavam em Cuité até realizar atividades profissionais ou estudantis na referida instituição de ensino superior. 
Ao investigarmos a formação de demandas por parte dos membros do CES, a demanda habitacional apresentou-se mais intensa em relação às demais. Logo, nos dedicaremos a reflexões mais detalhadas deste fato na subseção seguinte.

\section{Expansão da malha urbana cuiteense e valorização do solo urbano}

A presença dos docentes, servidores e alunos do CES tem interferido diretamente no arranjo do espaço urbano de Cuité. Grande parte destas pessoas passou a residir no município para viabilizar suas atividades de trabalho ou estudo. Desse modo, elevaram a demanda por habitações, que, associada à escassez, possibilitou o aquecimento no setor imobiliário, causou a expansão da área urbana e uma alta inflação nesse setor.

A comunidade acadêmica que passou a residir na área urbana ocupa domicílios locados ou próprios. Uma parcela de 16,9\% ocupando pensionatos, hotéis, repúblicas, casa de familiares, amigos e residência universitária, enquanto $20,5 \%$ residem em habitações próprias e 62,6\% ocupam habitações locadas. De tal forma, esses dois últimos grupos compõem uma nova demanda habitacional para o mercado imobiliário, que, visando atender a essa demanda, aumentou as construções residenciais e, consequentemente, as transações comerciais de locação e venda de imóveis.

Habitar é uma necessidade fortemente relacionada ao poder econômico de cada indivíduo ou grupo social. A moradia é apenas uma entre as necessidades humanas apropriadas para alimentar a lógica do capital. Os fornecedores de produtos e serviços imobiliários estão relacionados à regularização de bens necessários à manutenção diária da sociedade; e promovem a construção, o financiamentos, a comercialização, a organização, a incorporação e o controle dos terrenos e imóveis. Dessa forma, possuem cada 
vez mais acesso aos meios de adquirir capital. O espaço é uma condição geral de existência e reprodução da sociedade. No modo de produção capitalista, ele é utilizado como meio de produção para a geração de mais-valia [...], sendo, neste sentido, consumido produtivamente (Botelho, 2007, p. 22).

O mercado imobiliário atuante no espaço urbano cuiteense tem se dedicado à construção de moradias e venda de terrenos em loteamentos abertos e fechados. A partir de dados cedidos pela Secretaria Municipal de Infraestrutura e Serviços Urbano de Cuité, foi contabilizado um total de dezenove loteamentos comercialmente ativos e que estão regularmente registrados ${ }^{44}$ pelos órgãos municipais. A Tabela 10 lista esses loteamentos e apresenta suas respectivas áreas e anos de registros.

Tabela 10 - Cuité. Loteamentos urbanos segundo área e ano de registro

\begin{tabular}{lcc}
\hline Loteamento & Área (M2) & Ano de Inscrição \\
\hline Jardim Basílio Fonsêca & 206.750 & 1989 \\
\hline Planalto das Mansões & 134.020 & 2000 \\
\hline Jardim Panorâmico & $92.400,00$ & 2004 \\
\hline Bela Vista & 73.500 & 2007 \\
\hline Substação & 36.000 & 2007 \\
\hline São Francisco I & 48.000 & 2008 \\
\hline São Francisco II & 40.000 & 2008 \\
\hline Jardim dos Baóbas I & $200.484,06$ & 2008 \\
\hline Jardim dos Baóbas II & $61.231,77$ & 2009 \\
\hline Euclides Bezerra Cavalcante & 26.000 & 2009 \\
\hline
\end{tabular}

4 Cabe destacarmos que, em nossa pesquisa não contabilizamos ou enfatizamos a comercialização e produção de bens imobiliários não legalizados junto à administração municipal. 


\begin{tabular}{lcl}
\hline Jardim Trevo & $659.423,45$ & 2009 \\
\hline Parque do Patrício & 82.000 & 2010 \\
\hline Euflácio da Silva & 16.157 & 2010 \\
\hline Chã da Mata & 88.000 & 2011 \\
\hline Chã da Serra & 22.562 & 2011 \\
\hline Santa Maria & 132.800 & 2012 \\
\hline Nova Cuité & 126.000 & 2013 \\
\hline Cuité Ville & $26.351,40$ & 2013 \\
\hline Renascer da Serra & $107.419,80$ & 2013 \\
\hline
\end{tabular}

Fonte: Secretaria Municipal de Infraestrutura e Serviços Urbano.

Apenas três loteamentos antecedem o ano de 2006, são eles: Planalto das Mansões, Jardim Basílio Fonsêca e Jardim Panorâmico. Entretanto, de acordo com as informações cedidas pela Secretaria Municipal de Infraestrutura e Serviços Urbano, mesmo os loteamentos mais antigos tiveram aquecimento nas vendas no período de 2009 a 2014. Esses dados e informações corroboram a intensificação da criação e comercialização de terrenos urbanos após a implantação do CES.

Os loteamentos registrados ao ano de 2013 (Renascer da Serra, Cuité Ville e Nova Cuité) ainda não possuem residências construídas, assim, disponibilizam para venda somente os lotes. Já nos loteamentos mais antigos, realiza-se tanto a comercialização de terrenos quanto de casas.

Esses loteamentos distribuem-se no entorno da malha urbana nas diversas direções geográficas. Como pode ser comprovado na figura 17 , que apresenta a disposição dos loteamentos habitacionais da área urbana de Cuité. 
Figura 17 - Cuité, 2014: Disposição dos loteamentos habitacionais da área urbana

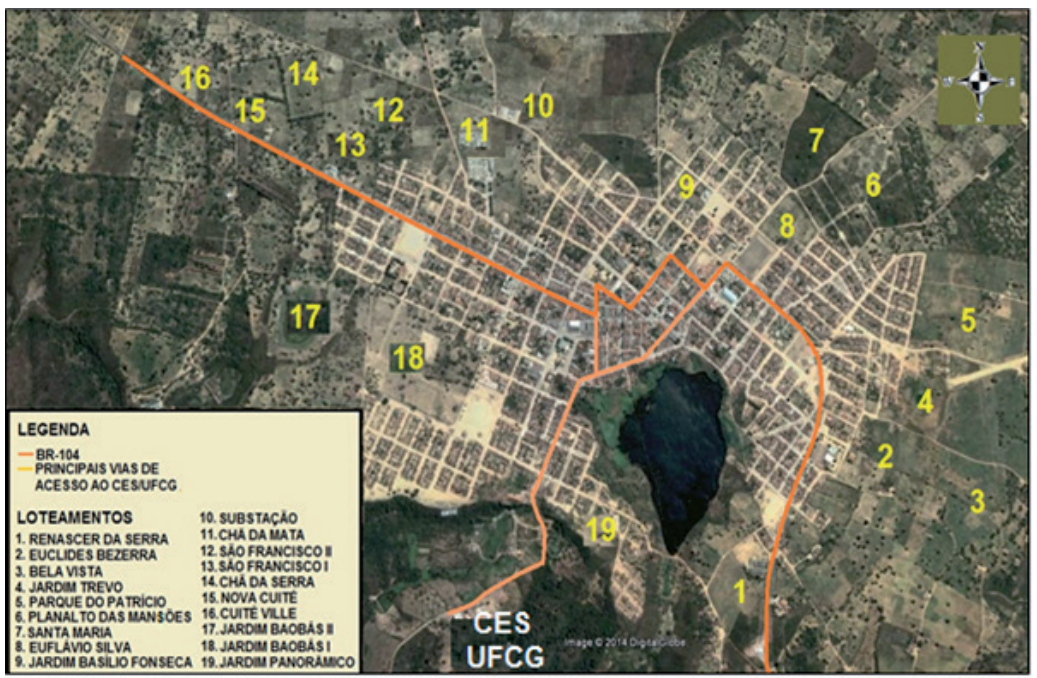

Fonte: Secretaria Municipal de Infraestrutura e Serviços Urbano. Pesquisa de Campo, 2014. Imagem: Google Earth, 2006. Adaptada por: Maria Verônica de Azevedo Gomes.

A implantação de loteamentos e, consequentemente, o crescimento da área urbana nas direções Sul e Sudeste, é inferior ao das demais direções. Este fato pode estar ligado, principalmente, a questões naturais do relevo, visto que essas áreas apresentam relevo acidentado, que mesmo não sendo um fator limitante à ocupação, desvaloriza economicamente o terreno no mercado imobiliário.

De acordo com Carlos (2008a), o preço da terra urbana está relacionado com a localização do terreno, com o acesso aos lugares contemplados com serviços e áreas naturais, com a infraestrutura urbana, com a privacidade e, em segundo plano, com questões relacionadas ao relevo, que implicam as condições e os custos da produção.

$\mathrm{Na}$ figura 17, constata-se que a malha urbana cuiteense se expandiu em torno da rodovia BR-104 e que o crescimento horizontal ao longo dessa via ainda se efetiva contemporaneamente. Segundo Villaça 
(2001), as vias regionais direcionam o crescimento horizontal das cidades, pois facilitam a acessibilidade intramunicipal e intrarregional. Os loteamentos Nova Cuité e Cuité Ville apresentam disposição à margem da BR-104 em direção Noroeste, no trecho que liga o município de Cuité ao município de Nova Floresta-PB - que, na sequência do percurso rodoviário, liga-se ao estado do Rio Grande do Norte.

Os loteamentos São Francisco I, São Francisco II e Chão da Serra não estão dispostos às margens da BR-104, mas também seguem a direção Noroeste dessa via de circulação. O loteamento Renascer da Serra situa-se no sentido Sul, também seguindo o sentido da BR, nesse caso, seguindo o trecho que liga o município à região central do Estado da Paraíba.

Segundo informações cedidas pela empresa imobiliária A.M.C.,55 praticamente todos os empreendimentos imobiliários situados em Cuité apresentam área aberta. Há exceção do Renascer da Serra e Cuité Ville, que serão condomínios fechados. Os projetos infraestruturais desses empreendimentos ainda não estão finalizados, mas preveem a existência de áreas de amenidades naturais e de todo um aparato de segurança, pavimentação, lazer e esporte.

Esses condomínios destinam-se a atender a demanda da parcela populacional mais abastada, pois são valorizados por apresentarem boas condições de infraestrutura interna e pela proximidade da principal via de circulação e de equipamentos de serviços. Este último fator refere-se ao fato de o condomínio Cuité Ville estar sendo construído em frente da Escola Técnica Estadual de Cuité e o condomínio Renascer da Serra situar-se nas imediações da casa de shows Cuité Hall.

Desse modo, esses empreendimentos vêm intensificar a desigualdade socioespacial urbana de Cuité. Como afirma Maia et al. (2013, p. 120), "produzem-se, portanto, áreas distintas, muitas vezes

5 Empresa do setor imobiliário, criada no ano de 2009, que presta serviços de venda de imóveis urbanos. 
segregadas (autossegregação e segregação induzida), contraditoriamente diferentes, tanto no que diz respeito ao rendimento médio e aos equipamentos instalados, como à própria morfologia urbana".

Além de colaborarem para expansão da cidade, os empreendimentos inserem aos poucos na área urbana cuiteense as novas formas de moradia que alimentam a ilusória ideia de espaços de felicidade, tranquilidade, segurança e harmonia com a natureza e com os demais habitantes.

Entretanto, a cidade apresenta realidades diversas, e a valorização do solo urbano obedece a inúmeras variáveis. Sendo assim, nem todas as áreas da cidade são valorizadas ou desvalorizadas por motivos comuns. Por exemplo: os loteamentos Jardim Basílio Fonseca e Planalto das Mansões, que atualmente dispõem de infraestrutura urbana mínima, possuem os maiores preços de terrenos e habitações do município. Essas áreas possuem apenas serviços de abastecimento de água e elétrico; não há pavimentação, saneamento, áreas de lazer e nem proximidade de equipamentos públicos ou comerciais.

Segundo as empresas A.M.C. e CKF-construção LTDA, ${ }^{66}$ a valorização desses loteamentos justifica-se pelo padrão dos imóveis construídos e pela concentração populacional de alta renda. Como afirma Botelho (2007, p. 35), "a especificidade do espaço das camadas superiores é signo de distinção social, participa do sistema de expressão e de reiteração simbólica da hierarquia das situações de classe".

Esses bairros constituem-se em áreas de segregação de igualdade socioeconômica, pelo fato de os moradores desses locais possuírem semelhante nível de renda e status social. Fato que é ressaltado por meio das propagandas e do marketing imobiliário, como demonstrado na figura 18 .

${ }^{6}$ Empresa imobiliária institucionalizada no ano de 2012 com a finalidade de promover a construção de imóveis habitacionais populares, e de médio e alto padrão. 
Figura 18 - Outdoor de propaganda de vendas imobiliárias da CKF-construção

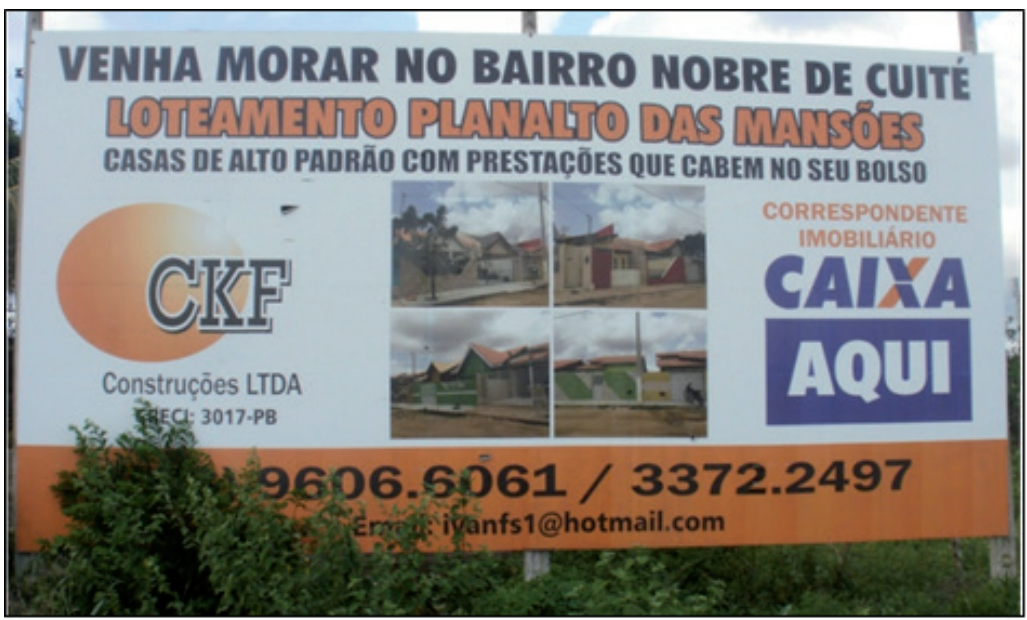

Fonte: Pesquisa de Campo, 2014.

Desse modo, formam-se os bairros nobres da cidade. Seja por meio dos condomínios fechados ou loteamentos abertos, essas áreas são visivelmente reconhecidas pelas suas "residências de alto padrão de construção, cujos preços podem ser deduzidos a partir dos anúncios de venda e de locação" (Maia et al., 2013, p. 140).

O preço estipulado para esses produtos é de responsabilidade dos agentes que os constroem ou comercializam, ou seja, pelos seus proprietários, baseado na situação em que o mercado se encontra. Botelho (2007, p. 23) afirma que o consumo e a produção do espaço urbano "estão inseridos no amplo processo de reprodução das relações de produção capitalista, na medida em que são guiados pelos ditames da propriedade privada, e são regulados pelas necessidades do capital em gerar valor excedente".

Considerando a lógica de sustentação do capital, quando a procura por esses produtos for maior que a oferta, maior será seu valor. Segundo Rodrigues (2003, p. 19), "um aspecto essencial da 
terra urbana é este: ter preço que não é definido pelo valor de produção. É uma mercadoria sem valor, cujo preço é definido pelas regras de valorização do capital em geral, pela produção social”.

O corretor de imóveis Sr. Adaildo Medeiros Costa $^{77}$ (que atua na área há dezoito anos, mas só a partir de 2009 pela empesa A.M.C) relata que até o ano de 2006 era possível adquirir um terreno de $250 \mathrm{~m}^{2}$ nas áreas mais valorizadas da cidade por um preço entre $\mathrm{R} \$ 3.000,00$ (três mil reais) a $\mathrm{R} \$ 4.000,00$ (quatro mil reais). Ao ano de 2014, nas mesmas localidades e com a mesma medida de área, os preços variavam entre $\mathrm{R} \$ 25.000,00$ (vinte e cinco mil reais) e 30.000,00 (trinta mil reais).

De acordo com dados fornecidos pela CKF-construção LTDA., no ano de 2014, o metro quadrado do terreno variava entre $\mathrm{R} \$ 60,00$ (sessenta reais) e $\mathrm{R} \$ 120,00$ (cento e vinte reais), dependendo as áreas da cidade onde se localizam. Como no ano de 2006 o preço médio do metro quadrado de terreno urbano era de $\mathrm{R} \$ 30,00$ (trinta reais), é possível constatar que houve uma valorização média de $300 \%$ em apenas oito anos - o que corresponde a uma valorização anual média de 37,5\%.

O Sr. Adaildo Medeiros Costa relata que os aluguéis de residências têm aumentado em uma margem aproximada ao aumento dos terrenos. Uma casa disponível a locação até o ano de 2006 por $\mathrm{R} \$ 100,00$ (cem reais) em 2014 estava acessível por cerca de $\mathrm{R} \$$ 400,00 (quatrocentos reais).

Ao final da reflexão sobre as dinâmicas socioespaciais da área urbana de Cuité, consideramos ser plausível afirmar que esta porção espacial passa pelos processos de valorização da terra urbana e de expansão territorial ao incorporar novas áreas, que se caracterizam pela formação de loteamentos habitacionais horizontais.

Entrevista cedida dia 07 de Abril de 2014, Centro, Cuité - PB. 


\section{Considerações finais}

Abstrair a realidade de uma porção espacial para interpretá-la com consciência exige muito empenho, contemplação e reflexão. Exercício que nos dedicamos ao analisar as questões intraurbanas do município de Cuité desinentes da existência do Centro de Educação e Saúde-CES da Universidade Federal de Campina Grande-UFCG. Compreendo o CES como objeto geográfico, é plausível afirmar que promove alterações nas questões funcionais, sociais, demográficas, econômicas e espaciais intraurbanas.

A presença do campus universitário atribuiu à Cuité um serviço especializado que concedeu à cidade mais valor em nível regional e também uma nova funcionalidade. Incentivou as esferas capitalistas a investirem em novos serviços educacionais das mais diversas modalidades, que abrangem o ensino básico, técnico, profissionalizante e superior. Assim, o crescimento na prestação de serviços voltados à educação é um dos fatores que impulsiona a reconfiguração da funcionalidade local, na medida em que a função econômica predominantemente agrícola, existente até o fim da década de 1980, começa a ceder espaço para o setor de serviços educacionais.

Identificamos que esta instituição não somente atrai novos investimentos, como também atrai pessoas pela oferta de formação educacional e emprego. A clientela é oriunda dos mais diversos locais do Brasil, em espacial de outros municípios da Paraíba. Uma minoria dos membros dessa comunidade universitária reside em municípios próximos a Cuité e desloca-se diariamente para realizar suas atividades no CES. Outra parcela fixou moradia permanentemente no referido município. E parcela, numericamente mais significante, fixou moradia nesta cidade em períodos letivos, assim, retorna para seu município de origem em recessos, fins de semana ou feriados. 
Os alunos e os profissionais de diversas áreas e funçôes interagem com a população cuiteense, favorecendo a intensificação do processo de trocas culturais, a geração de eventos harmoniosos e conflituosos e a ampliação das relações socioterritoriais em que a cidade está envolvida. Além disso, essa comunidade vem colaborando para a ampliação do fluxo de pessoas, de veículos e de informações, para as transformações demográficas e para o aumento da demanda por serviços e por comércio.

A soma dessa parcela demográfica ao contingente demográfico cuiteense tornou ainda mais visível a necessidade de investimentos que estimulem o crescimento e a diversidade de atividades de comércio e de serviços locais, como também de investimentos em infraestrutura urbana.

Concluímos que os investimentos do poder público e do mercado não estão sendo suficiente de acordo com demandas criadas, pois, ainda são pontuais e majoritariamente atendem às necessidades mais básicas. Diversos empreendimentos particulares destinam-se ao lazer, como as piscinas de aluguel, as casas de shows e de festas.

O aquecimento no setor imobiliário é outro exemplo de fenômeno decorrente deste processo migratório. A fixação, mesmo que periódica, de parte dos alunos e funcionários do CES tornou crescente a procura por moradia. Tal fato associado à baixa oferta de imóveis e terrenos destinados à locação e comercialização possibilitou ao setor imobiliário elevar produção e os preços destes bens e serviços, gerando a expansão da área urbana e uma alta valorização imobiliária nas mais diversas áreas da cidade.

O setor imobiliário tem investido maciçamente na produção de loteamentos habitacionais que ofertam tanto lotes de terras quanto residências já construídas; e, mais recentemente, nos condomínios fechados que inserem em Cuité novos padrões de moradia.

O alto preço dos imóveis urbanos viabilizou a criação de espaços de maior exclusão da população mais pobre do acesso aos 
direitos básicos na vida citadina, ampliando a segregação socioespacial nesse novo período de sua (re)produção.

Essa expansão territorial urbana ocorreu com rapidez e não dispõe do controle e da organização necessários por parte dos órgãos públicos. Até mesmo os bairros mais valorizados pelo mercado, por concentrar a população local de alto poder aquisitivo, estão crescendo sem infraestrutura que responda suficientemente às necessidades da sociedade.

Desse modo, para que haja maior crescimento e desenvolvimento em Cuité, é preciso que o Estado, na criação e na manutenção das estruturas urbanas, viabilize melhorias econômicas e sociais; e que a organização espacial se processe nos seus níveis político-administrativos municipal, estadual e federal, como também, que haja maior injeção de capital privado na realização de diversas atividades do mercado.

A partir das descobertas advindas de nossa pesquisa, cremos ter caminhando para o encontro de detalhes inerentes ao nosso objeto de pesquisa. Consideramos que os pontos aqui expostos e discutidos visam contribuir com as discussões relacionadas ao espaço urbano, no estudo das pequenas cidades e na releitura do processo de interiorização da educação superior no Brasil. Os dados e informações apresentados e discutidos apresentam-se como um passo inicial para investigações mais profundas, tanto no que se refere à participação da comunidade do CES quanto em relação aos investimentos qualitativos e quantitativos no mercado local. 


\section{Referências}

BOTELHO, A. O urbano em fragmentos: a produção do espaço e da moradia pelas práticas do setor imobiliário. São Paulo: Annablume - Fapesp, 2007.

CARLOS, A. F. A. A (re)produção do espaço urbano. São Paulo: Editora da Universidade de São Paulo: EDUSP, 2008a.

. A cidade. 8. ed. $2^{\text {a }}$ reimpressão. São Paulo: Contexto, 2008b.

IBGE. Cidades. 2010. Disponível em: http://www.ibge.gov.br/cidades. Acesso em: 12 maio 2015.

. Divisão Regional do Brasil 2017. Disponível em: https://www.ibge.gov. $\mathrm{br} /$ geociencias/organizacao-do-territorio/divisao-regional/15778-divisoes-regionais-do-brasil.html?=\&t=downloads. Acesso em: 10 jun. 2019.

MAIA, D.S. et al. "Campina Grande: dinâmica econômica e reestruturação urbana. Permanências e Transformações”. In ELIAS, D. et al (orgs.). Agentes econômicos e reestruturação urbana e regional: Campina Grande e Londrina. São Paulo: Outras Expressões, 2013. pp. 61-192.

MEC - MINISTÉRIO DA EDUCAÇÃO E CULTURA. 2008. O Programa Universidade para Todos - Prouni. Disponível em: http://prouniportal.mec. gov.br. Acesso em: 12 maio 2013.

2010. Expansão da educação superior e profissional tecnológica: mais formação e oportunidade para todos. Disponível em: http://portal.mec.gov.br/ expansao/images/apresentacao_expansao_educacao_superior14.pdf. Acesso em: 25 jun. 2012.

RODRIGUES, A. M. Moradia nas cidades brasileiras. 10. ed. São Paulo: Contexto, 2003.

SANTOS, M. Da totalidade ao lugar. São Paulo: Edusp, 2012a.

THOMSON, A. "Histórias (co) movedoras: história oral e estudos de migração". Revista Brasileira de História. v. 22, n. 44, p. 341-64. Tradução de Magda França Lopes. São Paulo, 2002.

UFCG - UNIVERSIDADE FEDERAL DE CAMPINA GRANDE. Secretaria de Projetos Estratégicos. PLANEXP - Plano de Expansão Institucional. 2005.

VILLAÇA, F. Espaço intra-urbano no Brasil. São Paulo: FAPESP, 2001. 